Herz 2021 · 46:138-149

https://doi.org/10.1007/s00059-021-05022-5

Accepted: 8 January 2021

Published online: 5 February 2021

(c) The Author(s) 2021

Renate B. Schnabel ${ }^{1,2}$. Gert Hasenfuß $\beta^{3} \cdot$ Sylvia Buchmann ${ }^{4} \cdot$ Kai G. Kahl $^{5}$. Stefanie Aeschbacher ${ }^{6} \cdot$ Stefan Osswald ${ }^{6} \cdot$ Christiane E. Angermann $^{7,8}$

' Universitäres Herz- und Gefäßzentrum Hamburg, Klinik und Poliklinik für Kardiologie, Universitätsklinikum Hamburg-Eppendorf, Hamburg, Germany

${ }^{2}$ Standort Hamburg/Kiel/Lübeck, Deutsches Zentrum für Herz-Kreislaufforschung (DZKH e. V.), Hamburg, Germany

${ }^{3}$ Herzzentrum, Klinik für Kardiologie und Pneumologie, Georg-August-Universität Göttingen, Göttingen, Germany

${ }^{4}$ Klinik für Anästhesie, operative Intensivmedizin und Schmerztherapie, Vivantes Klinikum Spandau—Berlin, Berlin, Germany

${ }^{5}$ Klinik für Psychiatrie, Sozialpsychiatrie und Psychotherapie, Medizinische Hochschule Hannover (MHH), Hannover, Germany

${ }^{6}$ Klinik für Kardiologie, Universitätsspital Basel, Basel, Switzerland

${ }^{7}$ Deutsches Zentrum für Herzinsuffizienz, Universität und Universitätsklinikum Würzburg, Würzburg, Germany

${ }^{8}$ Zentrum für seelische Gesundheit, Klinik für Psychiatrie, Psychosomatik und Psychotherapie, Universität Würzburg, Würzburg, Germany

\title{
Heart and brain interactions
}

\section{Pathophysiology and management of cardio-psycho-neurological disorders}

For example, autonomic dysfunction and inflammation may contribute to the increased cardiovascular mortality risk associated with depression [3], and a mutation of the ryanodine receptor sarcoplasmic reticulum calcium release channel has been shown to result in both cardiac arrhythmias and seizures [4]. Against this background, a bi-directional relationship between MHD and CVD is not surprising.

Here, we review interactions between CVD and MHD. This includes CVD and MHD in general, along with specific syndromes in which pre-existing neurological or psychiatric illnesses may predispose and contribute to CVD development (as in Takotsubo syndrome [TTS]), or in which psycho-physical stress, dysregulation of the interplay between innate immune and central nervous systems, and/or pre-existing CVD lead to secondary MHD and brain damage (as in peripartum cardiomyopathy [PPCM] and atrial fibrillation $[\mathrm{AF}]$ ).

Awareness of the complex bidirectional disease mechanisms in these settings is growing rapidly, but knowledge gaps remain, especially regarding the management of MHD in patients with these conditions. Multidisciplinary research that crosses organ borders is essential to uncover new disease mechanisms and allow for translation of new technologies, diagnostic procedures and preventive or innovative treatments from research settings into clinical practice to provide effective management and facilitate better outcomes in patients with cardio-psycho-neurological disorders.

\section{Links between cardiovascular diseases and mental health: general considerations}

Mental health disorders and CVD are common comorbidities [5]. The former are major causes of morbidity, mortality and poor quality of life in patients with CVD and are also independently associated with future CVD development $[6,7]$. Similar to the general population, MHD (especially depression) are more prevalent in women and younger people with CVD [8]. Importantly, MHD prevalence rates vary with CVD type and severity [5]. For example, depression was reported in $20 \%$ of patients with New York Heart As- 


\section{PREDISPOSING CONDITIONS - PSYCHOSOCIAL RISK FACTORS - PERSONAL CHARACTERISTICS \\ $\triangleright$ Chronic CV diseases \\ $\triangleright$ Acute tissue damage \\ (e.g., ACS, stroke) \\ $\triangleright$ Other diseases (e.g., diabetes) \\ $\triangleright$ Specific disorders (e.g., \\ Takotsubo syndrome, PPCM) \\ $\triangleright$ History of depression \\ $\triangleright$ Early childhood \\ adversities \\ $\triangleright$ Living circumstances \\ $\triangleright$ Environmental factors \\ $\triangleright$ Stressful events \\ $\triangleright$ Natural disasters \\ $\triangleright$ Age \\ $\triangleright$ Sex / gender \\ $\triangleright$ Genetic disposition \\ $\triangleright$ Attained educational level \\ $\triangleright$ Socioeconomic status}

\section{BIOLOGICAL CHANGES \\ $\triangleright$ Hypercortisolism \\ $\triangleright$ Neurohormonal/immune activation \\ $\triangleright$ Heart rate/blood pressure $\uparrow$ \\ $\triangleright$ Insulin resistance \\ $\triangleright$ Endothelial dysfunction/injury \\ $\triangleright$ Haemostatic changes \\ $\triangleright$ Pro-arrhythmic effects}

\section{CARDIOVASCULAR DISEASES}

$\triangle \mathrm{CAD} /$ myocardial infarction

$\triangle$ Myocardial/Valve disorders

$\triangleright$ Heart failure

$\triangleright$ Arrhythmias

$\triangleright$ Cardiac/non-cardiac comorbidities
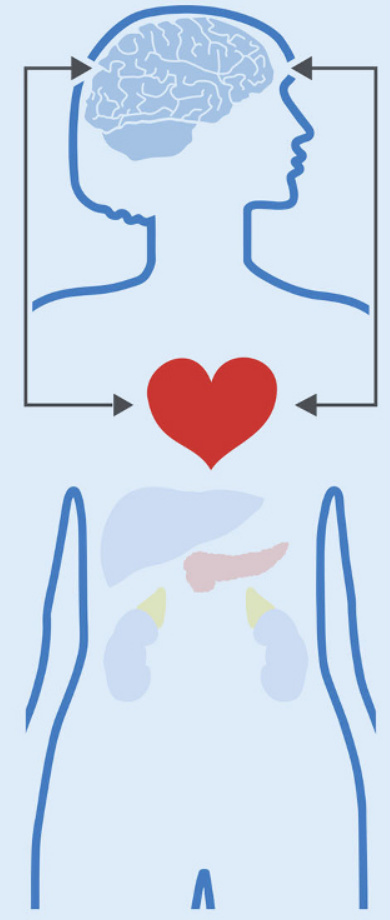

\section{CEREBRAL/MENTAL DISORDERS}

$\triangleright$ Cerebrovascular dysfunction

$\triangleright$ TIA/stroke

$\triangleright$ Grey matter loss

$\triangleright$ Depression

$\triangleright$ Cognitive dysfunction
Fig. $1 \varangle$ Pathophysiological links and biological and behavioural disease mechanisms potentially implicated in the development and progression of cardio-psychoneurological disorders. ACS acute coronary syndrome, $P P C M$ peripartum cardiomyopathy, CV cardiovascular, $C A D$ coronary artery disease sociation (NYHA) class I/II heart failure (HF), but in $42 \%$ of those with NYHA class III/IV HF in a study of 682 patients hospitalized with HF [9]. Furthermore, in addition to being correlated with NYHA class, depression prevalence and severity were also inversely related to quality of life [10].

\section{Pathophysiology}

Several studies, including large population-based analyses, report associations between MHD and incident CVD [11]. Bi-directional interrelations between major depression and CVD suggest that both diseases may share common pathophysiological pathways [12]. These include lifestyle factors (e.g. physical activity, smoking behaviour), dysfunction of endocrine systems (e.g. hypothalamus-pituitary-adrenal axis), and an imbalance of pro- and anti-inflammatory factors. Both MHD and CVD share genes involved in energy metabolism, stress system, circadian rhythm, in- flammation and neurotransmission. For example, covariation of depressive symptoms and coronary disease may in part be attributable to common genetic vulnerability potentially related to inflammation, serotonin pathways or mitochondrial energy metabolism [13, 14]. Associations between a functional sequence variant of the neuropeptide S receptor-1 gene, which regulates anxiety, and clinical outcomes and healthcare utilization in HF patients suggests the possibility that psychogenetic determinants may modu- 
Herz 2021 • 46:138-149 https://doi.org/10.1007/s00059-021-05022-5

(c) The Author(s) 2021

\section{R. B. Schnabel · G. Hasenfuß · S. Buchmann · K. G. Kahl·S. Aeschbacher · S. Osswald · C. E. Angermann}

\section{Heart and brain interactions. Pathophysiology and management of cardio-psycho-neurological disorders}

\begin{abstract}
Cardiovascular diseases (CVD) and mental

health disorders (MHD; e.g. depression, anxiety and cognitive dysfunction) are highly prevalent and are associated with significant morbidity and mortality and impaired quality of life. Currently, possible interactions between pathophysiological mechanisms in MHD and CVD are rarely considered during the diagnostic workup, prognostic assessment and treatment planning in patients with CVD, and research addressing bidirectional disease mechanisms in a systematic fashion is scarce. Besides some overarching pathogenetic principles shared by CVD and MHD, there are specific syndromes in
\end{abstract}

collaborations should be established to allow for more comprehensive understanding of the pathophysiology as well as appropriate and targeted diagnosis and treatment. In addition, we summarize current knowledge on the complex interactions between the cardiovascular and central nervous systems in Takotsubo syndrome and peripartum cardiomyopathy, and on the neurological and psychiatric complications of atrial fibrillation.

Keywords

Heart-and-brain axis · Mental health

disorders · Takotsubo syndrome · Peripartum cardiomyopathy · Atrial fibrillation

\section{Wechselwirkungen zwischen Herz und Hirn. Pathophysiologie und Behandlung kardio-psycho- neurologischer Gesundheitsstörungen}

\section{Zusammenfassung}

Kardiovaskuläre und psychische Erkrankungen (z. B. Depression, Angststörung, Kognitionsverlust) gehören zu den häufigen Volkskrankheiten, sind jeweils mit schlechter Lebensqualität und hoher Morbidität und Mortalität assoziiert und kommen häufig gemeinsam vor. Mögliche Zusammenhänge zwischen kardiovaskulären und psychischen Gesundheitsstörungen und ihre prognostischen Implikationen bleiben bisher bei Diagnostik und Therapie kardiovaskulärer Patienten weitgehend unberücksichtigt, und systematische wissenschaftliche Untersuchungen dazu sind selten. Neben prinzipiellen systemischen Wechselwirkungen gibt es syndromale Krankheitsbilder, bei denen entweder vorbestehende neurologische oder psychiatrische Krankheiten das Risiko für die Entstehung der Herzerkrankung erhöhen oder zum Krankheitsgeschehen beitragen (wie beim Takotsubo-Syndrom) oder bei denen eine gestörte Interaktion von angeborenem Immunsystem und zentralem Nervensystem und/oder vorbestehende Herzkrankheiten zur Entstehung von sekundären psychiatrischen oder neurologischen Krankheiten führen (wie bei der Peripartum-Kardiomyopathie oder dem Vorhofflimmern). Klinische Manifestation und Phänotyp kardio-psycho-neurologischer Krankheiten hängen vom individuellen somatischen, psychosozialen und genetischen Risikoprofil und von der Resilienz des Einzelnen $\mathrm{ab}$ und sind bei Männern und Frauen in mancher Hinsicht unterschiedlich. In diesem
Artikel wird erörtert, warum zum besseren Verständnis der Krankheitsentstehung und für die gezielte Diagnose und Behandlung solcher komplexer Erkrankungen multidisziplinäre Kooperationen wichtig sind. Außerdem wird der aktuelle Wissensstand zu den Wechselwirkungen zwischen kardialen und psychischen bzw. neurologischen Gesundheitsstörungen beim Takotsubo-Syndrom, der PeripartumKardiomyopathie und dem Vorhofflimmern zusammengefasst.

\section{Schlüsselwörter}

Herz-Hirn-Achse - Neuropsychiatrische Erkrankungen - Takotsubo-Syndrom · PeripartumKardiomyopathie · Vorhofflimmern late also such endpoints [15]. - Figure 1 shows a simplified schematic of key heart-brain interactions, which may induce systemic organ dysfunction and promote development and progression of different clinical phenotypes of both CVD and MHD. The pathogenetic importance of each factor varies in individual patients, and likely depends on the overall risk profile and personal resilience (i.e. the capacity to adapt swiftly and successfully in the face of physical and/or emotional challenges), plus the presence and severity of the somatic illness [16].

Similar to external stress, negative emotions might impact adversely on neurohormonal regulatory circuits. Autonomic nervous dysfunction may trigger multiple biological changes, including increased sympathetic tone, innate and adaptive immune system activation, higher circulating levels of stress hormones (e.g. cortisol and pro-inflammatory cytokines) and metabolic dysregulation [17]. Systemic inflam- mation may induce a procoagulatory state and endothelial dysfunction/injury. All these contribute to the development and progression of atherosclerosis, and increase the risk for arrhythmias such as AF, cardiac and cerebral clinical events and systemic disease in general [12, 18]. For example, recent evidence suggests that epicardial adipose tissue is a direct source of pro-inflammatory cytokines and could mediate various deleterious effects of systemic inflammation on cardiac structure and function, thus contributing 
to the pathogenesis of CVD, including calcific aortic stenosis [19]. Interestingly, transcatheter aortic valve replacement was shown to persistently improve depression and anxiety in such patients [20]. Other studies have demonstrated increased intra-abdominal and epicardial adipose tissue in individuals who are physically healthy but depressed, and in cardiac patients (e.g. congenital heart disease) with major depressive disorder $[14,21]$. Lastly, MHD may influence behavioural factors such as lifestyle, self-care and adherence to evidencebased therapies [22], which further contributes to a vicious circle of declining health, functional capacity and personal socioeconomic status.

\section{Management}

Mental health disorders can be easily overlooked or misinterpreted by physicians and patients [6] because signs and symptoms such as physical disability/ fatigue, loss of interest, anhedonia and sad mood, or eating and sleep disorders may be associated with both MHD and CVD, particularly at more advanced disease stages. Systematic screening for MHD using simple validated self-report tools offers the potential for early identification and targeted management, and is widely recommended [5]. Screening for MHD in cardiologist practices and hospitals would require minimal resources and efforts, but identification of MHD might necessitate increased downstream support from mental health providers, including immediate evaluation of suspected suicidality, and thus impact significantly on routine CVD management algorithms [5]. This could be one reason why MHD screening has not been widely implemented in CVD care settings, and why MHD remain underdiagnosed and undertreated. Additional research is needed to better determine the benefit of screening CVD patients for MHD [23]. Guideline-supported screening algorithms for MHD, especially depression, and additional diagnostic steps needed after a positive screening result are detailed in the work of Jha et al. [5].
Given the close correlation between CVD severity and the prevalence and severity of MHD, especially depression [12], treatments that improve cardiovascular function should also benefit coexisting mood disorders. The recent MEMS-HF study evaluating haemodynamic-guided HF management based on remote pulmonary artery pressure (PAP) monitoring demonstrated that decreases in PAP were associated with significant, persistent remission of depressive symptoms, and that larger PAP decreases resulted in greater depression remission and quality of life improvement [24]. This is the first time that an MHD (depression) has been linked with a treatable biological variable (haemodynamic congestion). Accordingly, standard care approaches should include disease-modifying treatments for CVD and associated comorbidities as well as MHD, and integrate needs-adjusted management of stressful signs and symptoms (e.g. sleep optimization, pain management) while improving patients' psychosocial functioning, healthcare competence and selfmonitoring/empowerment [12].

Specific antidepressant and anxiolytic treatments, including pharmacotherapy, psychological or behavioural interventions and/or physical exercise, have shown disparate effects on symptoms and clinical outcomes in patients with CVD, including post-stroke depression $[25,26]$. Due to their overall safety profile and effectiveness, selective serotonin reuptake inhibitors (SSRI) have emerged as first-line therapy for depression and anxiety in patients with CVD [25]. Evidence suggests that SSRI are safe in patients with stable CVD and after myocardial infarction, and may improve depressive symptoms and possibly prognosis (overview in [5]). However, SSRI had no effect on either depression or outcomes compared with clinical management alone in patients with symptomatic HF in two large randomized trials $[27,28]$, and dose-dependent QTc prolongation indicates increased risk for torsade-depointes arrhythmias [29]. Meta-analysis data suggest that SSRI may increase mortality risk in HF patients [30]. Few data are available on the safety and efficacy of newer antidepressants such as melatonergic agonists (agomelatine) and norepinephrine and dopamine reuptake inhibitors (bupropion) in patients with CVD. Adverse clinical effects such as changes in adiposity and insulin sensitivity, or (in experimental models) endothelial nitric oxide depletion and augmentation of oxidative stress, have been observed with some of the newer antipsychotics (e.g. risperidone, olanzapine or clozapine; $[31,32])$. These agents therefore seem to have the potential to cause complications that contribute to increased cardiovascular risk, necessitating careful benefit-to-risk assessment before use.

More advanced immune dysregulation as the major underlying cause of MHD, especially depression, might explain both the higher prevalence rates and the relative lack of benefit from antidepressants, particularly at more severe CVD stages. Thus, before antidepressant therapy is initiated, possible benefits should always be jointly evaluated by cardiologists and psychiatrists. Medications with anti-inflammatory properties (e.g. non-steroidal anti-inflammatories, cytokine inhibitors) have been shown to alleviate signs and symptoms of both CVD and depression [33]. In addition, recent clinical trials demonstrated that canakinumab and colchicine significantly reduce cardiovascular event rates in patients with coronary disease (reviewed by Nidorf et al. [34]). To what extent these drugs classes may also improve concurrent MHD requires further study.

\section{Takotsubo syndrome: neurological and psychiatric comorbidities}

Takotsubo syndrome (TTS), also termed "stress cardiomyopathy" or "broken heart syndrome", represents an acute reversible form of myocardial injury characterized by transient myocardial wall motion abnormalities, and is often accompanied by symptoms of acute heart failure [35]. "Takotsubo" refers to an apical ballooning pattern of the left ventricle during systole, which is the most common cardiac wall motion abnormality in patients with TTS and resembles a Japanese octo- 


\begin{tabular}{|c|c|c|}
\hline \multicolumn{3}{|c|}{ PREDISPOSING CONDITIONS - RISK FACTORS } \\
\hline $\begin{array}{l}\triangleright \text { Female sex } \\
\triangleright \text { Post-menopause } \\
\triangleright \text { Asthma/COPD } \\
\triangleright \text { Diabetes mellitus } \\
\triangleright \text { Genetic predisposition? }\end{array}$ & $\begin{aligned} \triangleright & \text { Psychotropic treatments } \\
& \text { (e.g., SNRI, ECT) } \\
\triangleright & \text { Neurological disorders } \\
& \text { (e.g., epilepsy, stroke) } \\
\triangleright & \text { Substance abuse }\end{aligned}$ & $\begin{array}{l}\triangleright \text { Psychiatric disorders } \\
\text { (e.g., depression, anxiety, } \\
\text { panic disorder) } \\
\triangleright \text { Neuro-cognitive } \\
\text { dysfunction }\end{array}$ \\
\hline $\begin{array}{l}\text { PHYSICAL TRIGGERS } \\
\text { (Examples) } \\
\triangleright \text { Trauma/surgery } \\
\triangleright \text { Severe infections } \\
\triangleright \text { Intoxication } \\
\triangleright \text { Cerebral insult/bleeding } \\
\triangleright \text { Migraine } \\
\triangleright \text { Gastrointestinal ulcer/bleeding } \\
\triangleright \text { Chemotherapy } \\
\triangleright \text { Giving birth }\end{array}$ & & $\begin{array}{l}\text { EMOTIONAL TRIGGERS } \\
\text { (Examples) } \\
\triangleright \text { Strong negative } \\
\quad \text { (and positive) emotions } \\
\triangleright \text { Natural disasters } \\
\triangleright \text { Challenging life events } \\
\quad \text { (job application, retirement) } \\
\triangleright \text { Losses (parter, bankruptcy) } \\
\triangleright \text { Personal conflicts } \\
\quad \text { (divorce, arguments) } \\
\triangleright \text { Fear }\end{array}$ \\
\hline $\begin{array}{l}\text { BIOLOGICAL MECHANISMS } \\
\triangleright \text { Altered limbic/autonomic } \\
\quad \text { processing } \\
\triangleright \text { Catecholamine excess } \\
\triangleright \text { Stress-related neuropeptides } \\
\quad \text { (Neuropeptide Y) } \\
\triangleright \text { Increased cardiac } \\
\quad \text { sympathetic sensitivity } \\
\triangleright \text { Cardiodepressant effects } \\
\triangleright \text { Microvascular dysfunction } \\
\triangleright \text { Myocardial stunning }\end{array}$ & & $\begin{array}{l}\text { CLINICAL FEATURES } \\
\triangleright \text { Angina } \\
\triangleright \text { Cardiac dysfunction } \\
\triangleright \text { Transient WMA beyond } \\
\quad \text { perfusion territories } \\
\text { (apical ballooning) } \\
\triangleright \text { Dynamic ECG-changes } \\
\text { (QT-prolongation, } \\
\text { T-wave inversion) } \\
\triangleright \text { Mild/moderate elevation } \\
\text { of cardiac biomarkers }\end{array}$ \\
\hline \multicolumn{3}{|c|}{ CLINICAL COURSE - COMPLICATIONS } \\
\hline $\begin{array}{l}\triangleright \text { Transient acute heart failure } \\
\triangleright \text { Normalization of cardiac } \\
\quad \text { function (within few weeks) } \\
\triangleright \text { LV outflow tract obstruction }(25 \%)\end{array}$ & $\begin{array}{l}\triangleright \text { Cardiogenic shock } \\
\triangleright \text { Arrhythmias } \\
\triangleright \text { Cardiac rupture } \\
\triangleright \text { Cardiac arrest }\end{array}$ & $\begin{array}{l}\triangleright \text { Systemic thromboembolism } \\
\triangleright \text { In-hospital mortality } \\
\quad \text { (up to } 5 \% \text { ) } \\
\triangleright \text { Recurrent TTS events }\end{array}$ \\
\hline
\end{tabular}

Fig. $2<$ Possible pathogenic mechanisms, clinical course and complications of Takotsubo syndrome. COPD chronic obstructive pulmonary disease; SNRI serotonin-norepinephrine reuptake inhibitors, ECT electroconvulsive therapy, WMA wall motion abnormality, ECG electrocardiogram, LV left ventricular, TTS Takotsubo syndrome pus trap. Other parts of the myocardium may also be affected; typically, wall motion abnormalities extend beyond the perfusion territory of one vessel $[35,36]$. - Figure 2 shows predisposing conditions and risk factors for TTS. Typically, TTS occurs in post-menopausal women, and there is a strong association with pre-existing psychiatric or neurological illnesses or with substance abuse. Frequently, but not always, TTS is preceded by physical or emotional triggers [36]. The estimated incidence in all patients with suspected ACS is $1-2 \%$, but TTS is likely to be underdiagnosed [37]. The International Takotsubo Registry showed that almost $90 \%$ of patients were female [38], although TTS may occasionally occur in males. The most common symptoms of TTS are acute chest pain and dyspnoea, which at first glance resemble ACS. However, in contrast to ACS, no relevant obstructive coronary lesions are seen on coronary angiography [35]. Although TTS is generally considered a benign disease, several observational studies reported rates of complications (e.g. cardiogenic shock) and clinical endpoint events that were comparable to or even worse than those of ACS. For example, in a German series of 286 patients with TTS, the 1-year mortality rate did not differ from that in a matched group of 286 patients with STsegment elevation myocardial infarction (STEMI), while the mortality rate after a mean $3.8 \pm 2.5$ years of follow-up was even higher in patients with TTS versus STEMI (24.7\% vs. $15.1 \%, p=0.02$; [39]). 


\begin{tabular}{|c|c|c|c|c|}
\hline \multicolumn{5}{|c|}{ Takotsubo - InterTAK Diagnostic Score } \\
\hline Criteria & Points & Prediction of TTS & OR (95\% Cl) & P-value \\
\hline Female sex & 25 & $\longmapsto-1$ & $68(29.0-163-7)$ & $P<0.001$ \\
\hline Emotional trigger & 24 & $\longmapsto$ & $65(20.3-205.8)$ & $P<0.001$ \\
\hline Physical trigger & 13 & $\mapsto-1$ & $8.7(4.6-17.3)$ & $P<0.001$ \\
\hline Absence of ST-segment depression & 12 & $\mapsto$ & $7.2(3.1-16.8)$ & $P<0.001$ \\
\hline Psychiatric disorders & 11 & $\mapsto$ & $7.0(3.1-15.5)$ & $P<0.001$ \\
\hline Neurologic disorders & 9 & $\longmapsto$ & $4,9(2.2-11.3)$ & $P<0.001$ \\
\hline QTc prolonation & 6 & $\mapsto$ & $2.8(1.3-5.7)$ & $P<0.006$ \\
\hline & $\overline{100}$ & 0.1 & & \\
\hline
\end{tabular}

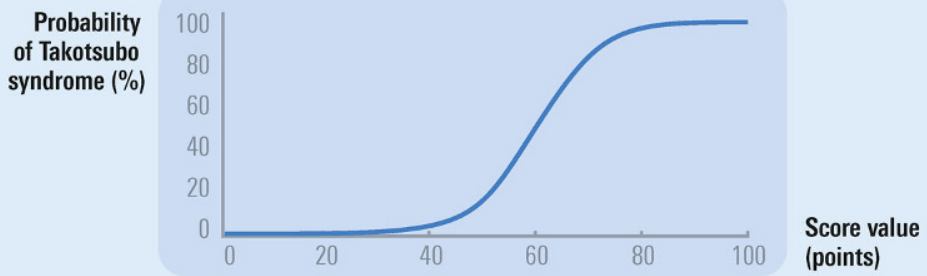

Fig. $3 \Delta$ Predictors of the diagnosis of Takotsubo syndrome (TTS) using multiple logistic regression analysis based on odds ratio $(O R)$ values for criteria used to build the InterTAK diagnostic score (top panel). A summary score is calculated from each individual score, which facilitates differentiation of Takotsubo syndrome from acute coronary syndrome (bottom panel). OR Odds Ratio, $\mathrm{Cl}$ confidence interval. (Modified and reprinted from Ghadri et al., 2017 [44] with permission)

These findings are concordant with data from the largest TTS registry to date [38], and suggest that TTS may not be as benign as previously assumed, and that patients with TTS need to be monitored long term, similar to those after STEMI.

\section{Pathophysiology}

The pathobiology of TTS is largely unknown, but suggested mechanisms include hypoconnectivity of central brain regions leading to altered limbic and autonomic processing in response to stress [40], and excess liberation of neurohormones and neuropeptides (e.g. neuropeptide $\mathrm{Y}$ ) in response to stressful events [36]. The increased risk of TTS development in patients with pre-existing neuro-psychiatric illnesses might be due to both an exaggerated catecholaminergic response and increased sensitivity of the myocardium to catecholamines, all of which may exert direct cardiotoxic effects and induce microvascular dysfunction and myocardial stunning [36]. In line with the concept of sympathetic activation, elevated norepinephrine levels in the coronary sinus have been found in patients with TTS, suggesting increased myocardial catecholamine release [41].
In an in vitro induced pluripotent stem cell model of TTS, enhanced $\beta$-adrenergic signalling and higher sensitivity to catecholamine-induced toxicity were identified as mechanisms associated with TTS [42]. In addition to myocardial dysfunction and injury, all these processes lead to dynamic ECG changes and moderate elevation of cardiac biomarkers in affected patients, and are referred to as "neurogenic stunning myocardium" (see Medina de Chazal et al. for more details; [36]).

Activation of the hypothalamic-pituitary-adrenal axis might link emotional stress and clinical TTS phenomena. In addition, pathways implicating female sex hormones could be important, given that $90 \%$ of TTS patients are women. Oestrogens may modulate catecholamineinduced vasoconstriction and upregulate endothelial nitric oxide (NO) synthase. Therefore, oestrogen supplementation may attenuate glucocorticoid and catecholamine responses to mental stress in perimenopausal women [43].

\section{Management}

Diagnosing TTS is often challenging, and there is currently no non-invasive tool available to facilitate conclusive diagnosis of TTS. Instead, cardiac catheterization is the method of choice to exclude or confirm TTS. The InterTAK Diagnostic Score was developed by the International Takotsubo Registry to aid physicians in assessing the likelihood of TTS ( $\bullet$ Fig. 3; [44]), but diagnostic criteria continue to be disputed (see Ghadri et al. for more details; [35]). All components of this score can be obtained in the emergency department and do not require cardiac imaging. However, without invasive assessment, a definitive diagnosis is only possible by demonstrating reversibility of the condition.

The aims of treatment for TTS are decongestion and haemodynamic support, and interventions need to be tailored to individual presentation patterns [36]. For example, in hypertensive patients with left ventricular (LV) outflow tract obstruction (as may occur with apical ballooning), arterial vasodilators must be used with caution to avoid aggravation of this complication. Guideline-directed medical therapy (GDMT) is recommended. However, no data from larger randomized trials are available regarding the efficacy of renin-angiotensinaldosterone system (RAAS) blockers and $\beta$-blockers in TTS patients. As outlined by a recent review, pre-existing psychiatric comorbidity requires special attention [45]. The International Takotsubo Registry demonstrated that TTS patients had significantly more depression and anxiety than ACS patients in general, even after controlling for age and sex [35]. Rapid up-titration of certain psychotropic agents (e.g. serotonin-norepinephrine reuptake inhibitors [SNRI], lithium) that tend to increase endogenous catecholamines, or electroconvulsive therapy (which also induces a transient abrupt increase in catecholamine levels), may predispose to TTS development [45]. These observations further support the concept of a causal role of excess catecholamines in this syndrome.

Long-term management strategies for psychiatric comorbidities in TTS patients, including psychotropic measures, are poorly delineated. The use of various antidepressants known to increase 
catecholamine levels should be avoided because of their known association with incident TTS [35]. Selective serotonin inhibitors (SSRI) may be considered to treat depression and anxiety in TTS, but there is currently a lack of data in this area [45]. However, a retrospective study of 78 patients with TTS showed increased mortality and delayed recovery of LV function in those taking SSRI [46], an observation that may caution also against the use of this substance class. Overall, there is currently no evidence of therapeutic benefit from any psychotropic therapy in TTS in the literature, and treatments that could prevent recurrence of TTS are unknown.

\section{Peripartum cardiomyopathy: depression and post-traumatic stress disorder}

Peripartum cardiomyopathy (PPCM) is an idiopathic cardiomyopathy presenting with LV systolic dysfunction (LV ejection fraction $[\mathrm{LVEF}]<45 \%$ ) with or without LV dilatation plus signs and symptoms of HF. Usually, PPCM occurs toward the end of pregnancy or in the first months after delivery. It affects about 1 in 1000 pregnancies worldwide, but incidence rates vary widely by ethnic/racial background and region; African and African American women are at a higher risk of developing PPCM. - Figure 4 shows predisposing conditions and risk factors for PPCM, including, for example, ethnicity, maternal age, multiparity and pre-eclampsia. In contrast to TTS, pre-existing MHD or neurological illnesses are not among the risk factors for PPCM. Peripartum cardiomyopathy has recently been reviewed, for example, by Davis et al. [47], Honigberg et al. [48] and Bauersachs et al. [49]. The majority of women with PPCM are diagnosed after delivery, but there are large regional differences in the frequency of reported antepartum symptom onset [50]. D Figure 4 details the outcomes of 739 participants in a multinational European Society of Cardiology (ESC) EURObservational Research Programme registry, in which the average 6-month mortality rate for women with PPCM was 6\%, with marked regional variability [50]. This rate is lower than previously reported [47]. Fewer than $50 \%$ of women had experienced normalization of LVEF at this time. By contrast, $>70 \%$ of a German cohort of 66 PPCM patients undergoing early treatment with the dopamine D2-receptor agonist bromocriptine and long-term GDMT had improvement in LVEF to $>50 \%$ at the 5 -year follow-up, but other cardiovascular disorders such as $\mathrm{AF}$ or hypertension were common [51]. A markedly increased risk for various malignancies both before and after PPCM diagnosis has been reported, possibly in association with specific genetic factors that seem to link PPCM and cancer [52].

Information on MHD following a diagnosis of PPCM is scarce. Screening for MHD with self-administered questionnaires revealed high prevalence rates of depression (32\%; [53]), generalized anxiety disorders (53\%; [53]) and impaired quality of life [54] in women with an established PPCM diagnosis. Using a Structured Clinical Interview, significant MHD was diagnosed in $65 \%$ of 40 women with PPCM; compared with post-partum women without PCCM, those with PCCM had a fourfold higher prevalence of major depression, a sixfold higher prevalence of panic disorder and a 14-fold higher prevalence of posttraumatic stress disorder in this study [54].

\section{Pathophysiology}

The aetiology of PPCM is incompletely understood and likely multifactorial. Suggested, but yet unproven pathogenetic mechanisms are shown in - Fig. 4. Prolactin (secreted from anterior pituitary gland) is cleaved by cathepsin D (activated by oxidative stress) into a 16KDa fragment, which triggers endothelial dysfunction and apoptosis. Vascular damage leads to release of microRNA (mRNA)-146a and other mRNAs, which block important pathways thus inducing myocardial injury and metabolic insufficiency. Soluble fms-like tyrosine kinase receptor 1 (sFLT-1) produced by the placenta sequesters vascular endothelial growth factor (VGEF). Lack of
VEGF leads to vascular and myocardial damage via several downstream pathways. Frequent occurrence of MHC is consistent with observations in severe CVD in general [5, 6]. However, in women with PPCM, impairment of the tryptophan metabolism has been reported, which increases the synthesis of quinolinic acid, with an associated reduction of serotonin synthesis, leading to reduced serotonin levels and increased production of the pro-inflammatory and MHD-promoting kynorenin, thus possibly providing a more specific explanation for the high incidence rates of MHC, especially depression, in women with PPCM [54]. This is compatible with the concept that (like certain infections) excessive psycho-physical stress may distort the interplay of the innate immune and central nervous systems, and implicates activation of toll-like receptors (e.g. TLR-4, the transcription factor NF-kB, or the inflammasome NLRP3), as well as the secretion of interleukin- 1 beta, interleukin- 6 and other factors of the innate immune response, thus causing general symptoms of disease, but also adding to depression and anxiety [55]. Furthermore, patients with PPCM have higher levels of the depressionassociated microRNA (miR)-30e [54]. Given that miR-30e impairs signalling pathways of the serotonin $1 \mathrm{~A}$ receptor [56], it may also contribute to incident depression in women developing PPCM. Lastly, a connection between treatment with bromocriptine and MHD cannot be excluded [57].

\section{Management}

Treatment of PPCM during pregnancy requires modifications to ensure foetal safety $[47,48]$. After delivery, standard GDMT includes decongestive treatment, neurohormonal inhibitors, vasodilators and device therapies in selected patients in addition to specific pathophysiologydirected treatment with bromocriptine [58]. Improvement of HF symptoms as a result of these measures will likely also benefit the patients' psychological situation. In view of the high prevalence of MHD in PPCM patients, psychiatric assessment and screening for post-trau- 


\section{PREDISPOSING CONDITIONS - RISK FACTORS}

$\begin{array}{lll}\triangleright \text { Ethnicity (African-American) } & \triangleright \text { Obesity/nutritional deficits } & \triangleright \text { Preeclampsia } \\ \triangleright \text { Maternal age }(>30-35 \text { years) } & \triangleright \text { Previous PPCM } & \triangleright \text { Gestational DM } \\ \triangleright \text { History of cardiac disorders } & \triangleright \text { Multiple pregnancies } & \triangleright \text { Hypertension } \\ \text { (e.g., myocarditis) } & \triangleright \text { Lifestyle habits } & \triangleright \text { History of cancer }\end{array}$

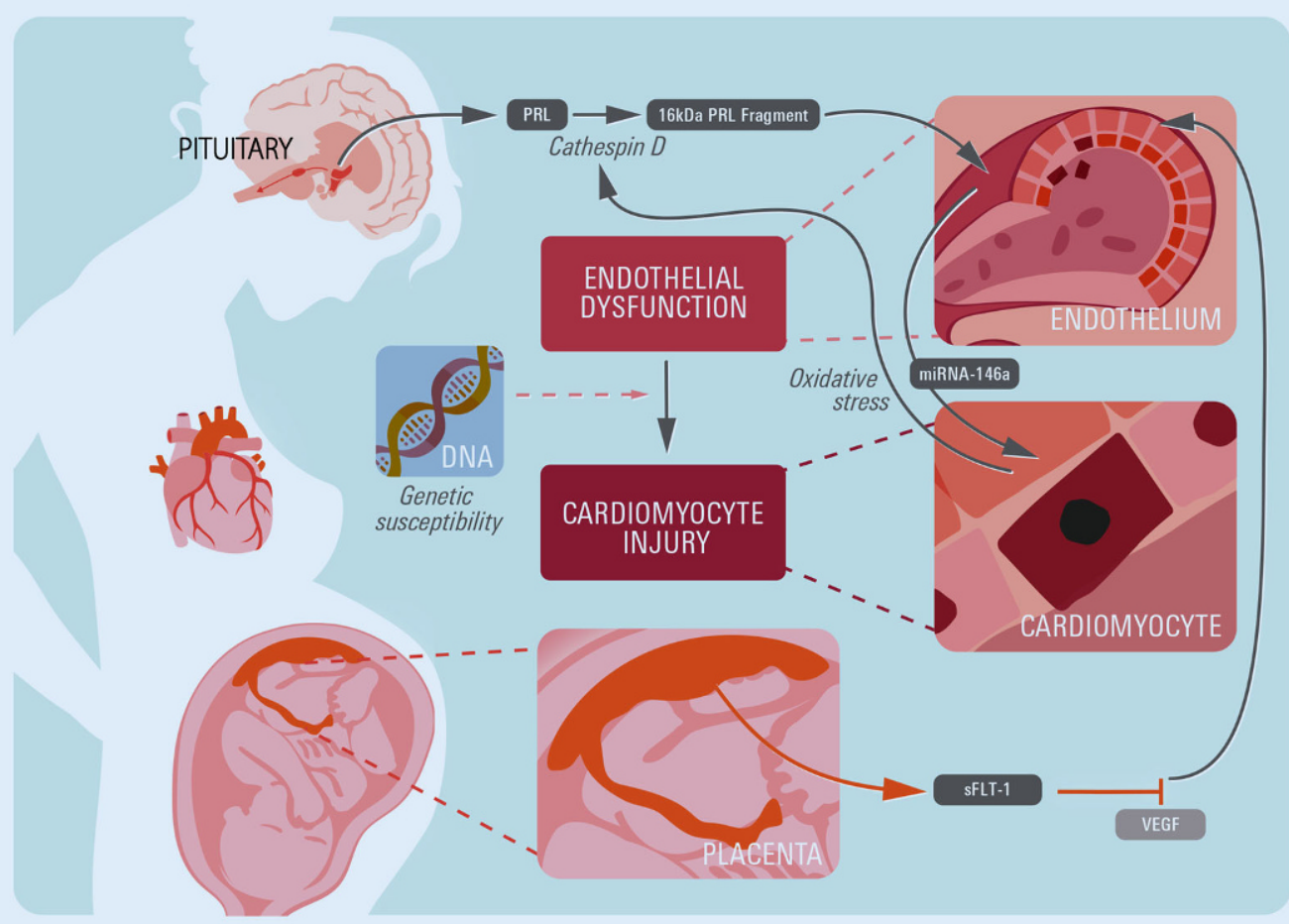

\section{TIME OF DIAGNOSIS - CLINICAL FEATURES}

$\triangleright$ Diagnosis before birth: $<10-40 \%$

$\triangleright$ Diagnosis post-partum: $60-100 \%$ (majority within 1 month)

$\triangleright$ HF signs/symptoms (60-70\% NYHA III/IV)

$\triangle$ LV systolic dysfunction

(LVEF $<45 \% \pm$ LV dilatation)

$\triangleright 60-70 \%$ LVEF $\leq 35 \%$ (symptomatic patients)
COMPLICATIONS - OUTCOMES (6 MONTHS)

$\triangleright$ High prevalence of mental health disorders (depression, anxiety, PSD)

$\triangleright$ Thromboembolism (7\%)

$\triangleright$ Myocardial recovery ( $\approx 50 \%$ )

$\triangleright$ Mortality (6\%)

$\triangleright$ Neonatal mortality (5\%)

$\triangleright$ Increased longer-term incidence of cancer
Fig. $4<$ Simplified representation of possible pathogenic mechanisms of peripartum cardiomyopathy (PPCM) and predisposing conditions/risk factors. Figure design inspired by Honigberg et al., 2019 [48]. Reported 6-month outcome data refer to Sliwa et al., 2020 [50]. DM diabetes mellitus, $H F$ heart failure, $L V$ left ventricular, LVEF left ventricular ejection fraction, NYHA New York Heart Association, PRL prolactin, PSD posttraumatic stress disorder, sFLT-1 fms-like tyrosine kinase receptor 1, VEGFvascular endothelial growth factor matic stress disorder and other affective diseases should be part of the routine clinical evaluation. Clinical care strategies must include detailed needs analysis to facilitate personalized supportive strategies such as multimodal patient-centred management, which may also help prevent PPCM recurrence during later pregnancies. In the case of severe depression or anxiety disorders, targeted psychopharmacological and/or psychotherapeutic interventions are recommended, although systematic studies evaluating their efficacy in PPCM are lacking.

\section{Atrial fibrillation and cognitive decline}

Atrial fibrillation is the most common arrhythmia and its prevalence increases rapidly in aging societies $[59,60]$. While relationships between $\mathrm{AF}$ and death, stroke and HF have long been established, more recent evidence suggests that patients with AF are also at higher risk of cognitive decline and developing dementia [61-66]. The Swiss Atrial Fibrillation Cohort Study (Swiss-AF) was a prospective, observational trial that enrolled patients aged $\geq 65$ years with $\mathrm{AF}$ and investigated the prevalence and incidence rates of clinically apparent versus subclinical brain lesions and their association with cognitive decline over time [67]. A total of 2400 patients underwent brain magnetic resonance imaging (MRI) at baseline and after 2 years, and extensive cognitive test- 


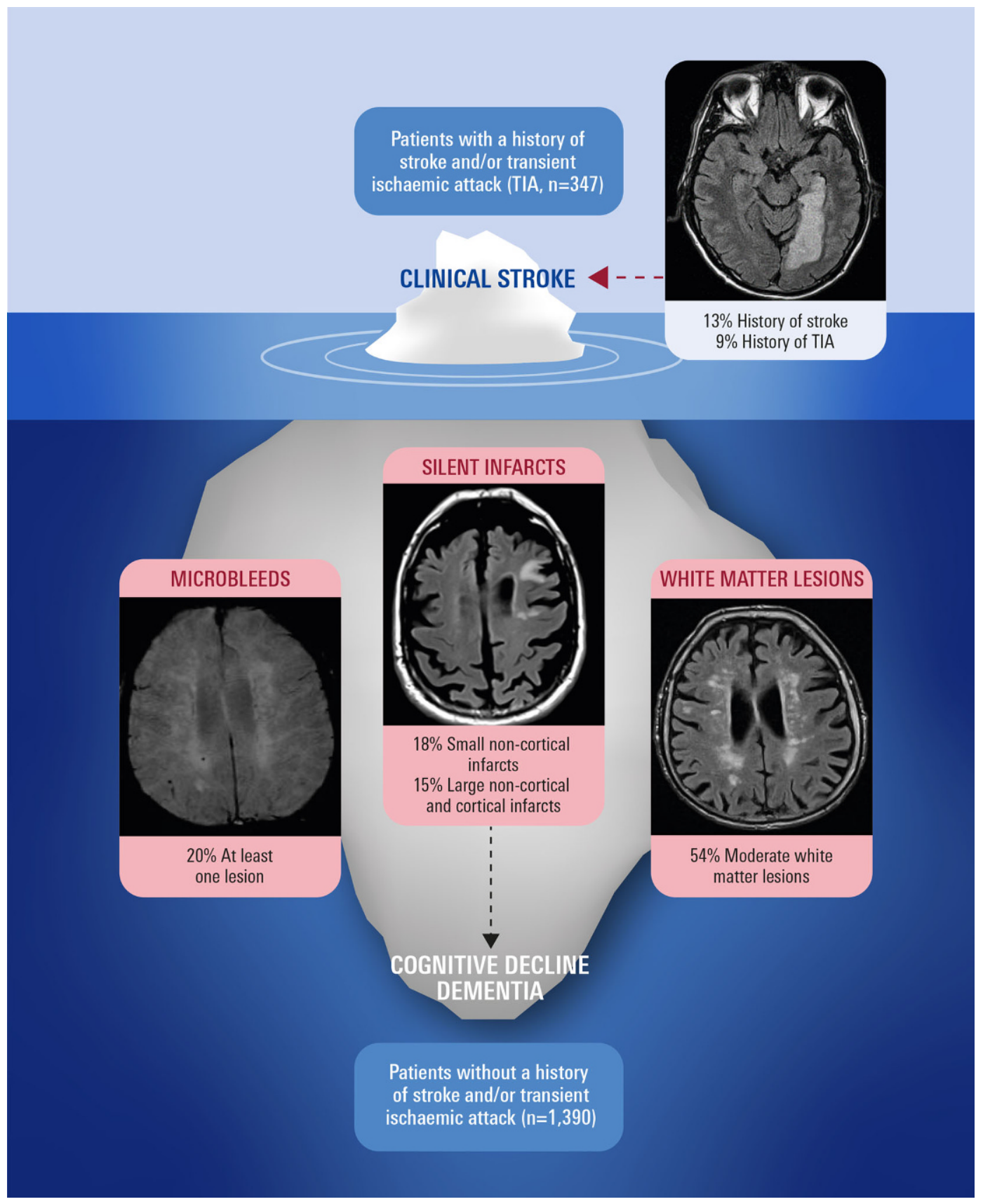

Fig. $5<$ The "tip of the iceberg". Prevalence rates of clinically apparent versus silent brain lesions in patients with atrial fibrillation (Swiss-AF prospective cohort study). (Modified and reprinted from Conen et al. 2019 [67] with permission) ing was performed annually. A crosssectional analysis from this data set revealed that clinically overt and, especially, silent brain lesions were highly prevalent (• Fig. 5). For example, white matter lesions (WML) of moderate (to severe) degree were found in $54 \%$ of patients without a history of stroke or transient ischaemic attacks. The presence and volume of both overt and silent large non-cortical and/or cortical infarcts (LNCCIs) on MRI were significantly associated with reduced neurocognitive function, even after multivariable adjustment for comorbidities. The lesions could, therefore, at least partly explain a higher risk of cognitive decline in patients with AF. Remarkably, 90\% of the Swiss-AF study population were on anticoagulants and/or receiving antithrombotic therapy at the time of the baseline MRI [67].

\section{Pathophysiology}

The increased risk of cognitive impairment associated with AF seems only partly explained by the generally accepted pathophysiological concept of a causal role of thromboembolic events, including both recurrent showers of microembolism and overt strokes [62]. Previous research described a decline in cognitive function in patients with incident $\mathrm{AF}$ even in the absence of clinical stroke, as well as a strong re- 


\begin{tabular}{|c|c|}
\hline \multicolumn{2}{|c|}{ Abbreviations } \\
\hline$A C S$ & Acute coronary syndrome \\
\hline$A F$ & Atrial fibrillation \\
\hline$C A D$ & Coronary artery disease \\
\hline$C O P D$ & $\begin{array}{l}\text { Chronic obstructive pulmonary } \\
\text { disease }\end{array}$ \\
\hline$C V$ & Cardiovascular \\
\hline$C V D$ & Cardiovascular diseases \\
\hline GDMT & $\begin{array}{l}\text { Guideline-directed medical } \\
\text { therapy }\end{array}$ \\
\hline$H F$ & Heart failure \\
\hline$L N C C I$ & $\begin{array}{l}\text { Large non-cortical and/or cortical } \\
\text { infarcts }\end{array}$ \\
\hline LVEF & Left ventricular ejection fraction \\
\hline$M H D$ & Mental health disorders \\
\hline$M R I$ & Magnetic resonance imaging \\
\hline NO & Nitric oxide \\
\hline NYHA & New York Heart Association \\
\hline PAP & Pulmonary artery pressure \\
\hline$P P C M$ & Peripartum cardiomyopathy \\
\hline RAAS & $\begin{array}{l}\text { Renin-angiotensin-aldosterone } \\
\text { system }\end{array}$ \\
\hline$s N f L$ & Serum neurofilament light chain \\
\hline SNRI & $\begin{array}{l}\text { Serotonin-norepinephrine } \\
\text { reuptake inhibitors }\end{array}$ \\
\hline SSRI & $\begin{array}{l}\text { Selective serotonin re-uptake } \\
\text { inhibitors }\end{array}$ \\
\hline TIA & Transitory ischaemic attack \\
\hline TTS & Takotsubo syndrome \\
\hline
\end{tabular}

lationship between the duration of $\mathrm{AF}$ (AF burden) and the risk of dementia in younger patients [61]. Concordantly, the Atherosclerosis Risk in Communities (ARIC) study demonstrated that patients with high AF burden (persistent AF, 100\%), but not those with lower AF burden (paroxysmal AF, 1-6\%), had lower executive and verbal cognitive test scores compared with patients without AF [68]. Interestingly, the observed associations remained significant after adjustment for prevalent clinical stroke and persisted even after further adjustment for subclinical events, thus not conclusively explaining the relationship between a higher AF burden and lower cognitive function. Beyond cerebrovascular embolism, clinically unrecognized (silent) strokes, microbleeds, and/or other brain lesions might have contributed to these findings [68]. In a recent Korean nationwide cohort study in AF patients treated with catheter ablation or medical therapy, ablation was associated with decreased dementia risk [69]. Notably, this relationship was also evident after censoring for stroke and adjusting for clinical confounders [69]. Together, these observations provide evidence that AF may provoke cognitive decline, and that coexistence of AF and dementia is not a chance association. However, to what extent the rhythm itself is responsible for the cognitive impairment, and to what extent eliminating the arrhythmia will diminish the likelihood of dementia requires further investigation. Other factors, such as increased systemic inflammatory activity and oxidative stress accompanying $\mathrm{AF}$ may also contribute to worsening cognitive function. In summary, vascular dementia appears to be a heterogenous syndrome probably caused by a variety of mechanisms, which remain poorly understood beyond the role of cortical infarcts and cerebral small-vessel disease, which is undisputed [70, 71].

Further studies addressing underlying mechanisms are underway. Thus, in Swiss-AF the serum neurofilament light chain (sNfL), an acute phase marker of neuronal damage, was found to be associated with different cardiovascular risk factors (e.g. blood pressure and diabetes) as well as with vascular brain lesions and lower cognitive function [67]. In addition, baseline sNfL predicted brain atrophy after 2 years (unpublished data). At the 2-year follow-up, new ischaemic brain lesions had occurred on MRI in $5.5 \%$ of patients; again, the vast majority of the lesions $(85 \%)$ were clinically silent and had occurred in patients on oral anticoagulation therapy. New white matter lesions were found in $18 \%$, and microbleeds in $11 \%$. Overall, progressive cognitive decline was found in most tested dimensions if new brain lesions were apparent on repeat MRI (unpublished data). However, to what extent these observations are causally related to the presence of $\mathrm{AF}$ remains to be clarified.

\section{Management}

Whether cerebral imaging, routine neurocognitive testing and routine analysis of markers such as sNfL should be used to screen for silent brain injury and whether implementation of such strategies into clinical routine care would improve prognosis is currently unknown. Recent findings suggest that effective oral anticoagulation may at least slow down cognitive decline and the development of dementia in patients with $\mathrm{AF}$ [72], and elimination of AF by ablation therapy seems to reduce the risk of dementia [69]. A more thorough understanding of the pathobiology of cognitive decline and dementia in patients with this common arrhythmia is required to promote development of efficacious preventive strategies.

\section{Conclusion}

Awareness of the pathophysiological links between cardiovascular diseases (CVD) and mental health disorders (MHD) is growing, along with better understanding of the basic mechanisms underlying their mutual impact on clinical outcomes, although significant gaps in knowledge remain. Imbalance in the interplay between the innate immune system and the central nervous system leading to systemic and cerebral inflammatory changes is emerging as a highlevel player mediating the complex interactions along the heart-brain axis. Currently, MHD remain largely underrecognized in patients with CVD. This prevents comprehensive collaborative diagnosis and management of cardiopsycho-neurological disorders. Routine screening for MHD by cardiologists could help to bridge this gap and therefore offer the chance to improve patient outcomes and quality of life. Joint efforts from cardiologists, neurologists and psychiatrists are needed to advance pathophysiological knowledge and determine evidence-based treatment strategies for MHD in CVD in general. In rare diseases such as Takotsubo syndrome and peripartum cardiomyopathy, prospective randomized multicentre trials are needed to generate better evidence for the efficacy of currently 
applied treatments, identify (based on deeper pathophysiological understanding) more specific therapies, and better delineate targeted diagnostic and therapeutic algorithms. More comprehensive appreciation of the complex pathogenetic mechanisms of atrial fibrillation development may also lead to novel treatment opportunities to prevent brain damage and dementia in many patients with this common CVD.

\section{Corresponding address}

\section{Christiane E. Angermann}

Deutsches Zentrum für Herzinsuffizienz, Universität und Universitätsklinikum Würzburg Am Schwarzenberg 15, 97078 Würzburg, Germany

Angermann_C@ukw.de

Acknowledgements. We thank Anna and Robert Wenzl, division of graphic design, UKE Würzburg, for creating all illustrations. English language editing support was provided by Nicola Ryan, BSc, an independent medical writer, who received financial compensation from the University of Würzburg.

\section{Compliance with ethical guidelines}

Conflict of interest. R.B. Schnabel, G. Hasenfuß, S. Buchmann, K.G. Kahl, S. Aeschbacher, S. Osswald, and C.E. Angermann declare that they have no competing interests.

For this article no studies with human participants or animals were performed by any of the authors. All studies performed were in accordance with the ethical standards indicated in each case.

Open Access. This article is licensed under a Creative Commons Attribution 4.0 International License, which permits use, sharing, adaptation, distribution and reproduction in any medium or format, as long as you give appropriate credit to the original author(s) and the source, provide a link to the Creative Commons licence, and indicate if changes were made. The images or other third party material in this article are included in the article's Creative Commons licence, unless indicated otherwise in a credit line to the material. If material is not included in the article's Creative Commons licence and your intended use is not permitted by statutory regulation or exceeds the permitted use, you will need to obtain permission directly from the copyright holder. To view a copy of this licence, visit http://creativecommons.org/licenses/by/4.0/.

\section{References}

1. Walker ER, McGee RE, Druss BG (2015) Mortality in mental disorders and global disease burden implications: a systematic review and meta- analysis. JAMA Psychiatry 72(4):334-341. https:// doi.org/10.1001/jamapsychiatry.2014.2502

2. World Health Organization (2017) World Health Organization cardiovascular diseases (CVDs) fact sheet. https://www.who.int/news-room/factsheets/detail/cardiovascular-diseases-(cvds). Accessed 20 Sept 2020

3. Kop WJ, Stein PK, Tracy RP et al (2010) Autonomic nervous system dysfunction and inflammation contribute to the increased cardiovascular mortality risk associated with depression. Psychosom Med 72(7):626-635. https://doi.org/10.1097/PSY 0b013e3181eadd2b

4. Lehnart SE, Mongillo M, Bellinger A et al (2008) Leaky Ca2+ release channel/ryanodine receptor 2 causes seizures and sudden cardiac death in mice. JClin Invest 118(6):2230-2245. https://doi.org/10. 1172/jci35346

5. Jha MK, Qamar A, Vaduganathan M et al (2019) Screening and management of depression in patients with cardiovascular disease: JACC state-ofthe-artreview. JAm Coll Cardiol 73(14):1827-1845. https://doi.org/10.1016/j.jacc.2019.01.041

6. Celano CM, Villegas AC, Albanese AM et al (2018) Depression and anxiety in heart failure: a review. Harv Rev Psychiatry 26(4):175-184. https://doi. org/10.1097/hrp.0000000000000162

7. Van der Kooy K, van Hout $\mathrm{H}$, Marwijk $\mathrm{H}$ et al (2007) Depression and the risk for cardiovascular diseases: systematic review and meta analysis. Int J Geriatr Psychiatry 22(7):613-626. https://doi.org/ 10.1002/gps.1723

8. Shah AJ et al (2014) Sex and age differences in the association of depression with obstructive coronaryartery diseaseand adverse cardiovascular events. J Am Heart Assoc 3(3):e741. https://doi. org/10.1161/jaha.113.000741

9. Freedland KE, Rich MW, Skala JA et al (2003) Prevalence of depression in hospitalized patients with congestive heart failure. Psychosom Med 65(1):119-128

10. Schowalter M, Gelbrich G, Störk S et al (2013) Generic and disease-specifichealth-related quality of life in patients with chronic systolic heart failure: impact of depression. Clin Res Cardiol 102(4):269-278

11. Harshfield EL, Pennells L, Schwartz JE et al (2020) Association between depressive symptoms and incident cardiovascular diseases. JAMA 324(23):2396-2405. https://doi.org/10.1001/ jama.2020.23068

12. Angermann CE, Ertl G (2018) Depression, anxiety, and cognitive impairment: comorbid mental health disorders in heart failure. Curr Heart Fail Rep 15(6):398-410. https://doi.org/10.1007/s11897018-0414-8

13. McCaffery JM, Frasure-Smith N, Dube MP et al (2006) Common genetic vulnerability to depressive symptoms and coronary artery disease: a review and development of candidate genes related to inflammation and serotonin. Psychosom Med 68(2):187-200. https://doi.org/10.1097/01. psy.0000208630.79271.a0

14. Kahl KG, Stapel B, Frieling H (2019) Link between depression and cardiovascular diseases due to epigenomics and proteomics: focus on energy metabolism. Prog Neuropsychopharmacol Biol Psychiatry 89:146-157. https://doi.org/10.1016/j. pnpbp.2018.09.004

15. Angermann CE, Kaspar M, Marx A et al (2017) A functional variant of the neuropeptide Sreceptor-1 gene modulates clinical outcomes and healthcare utilization in patients with systolic heart failure: results from the interdisciplinary network heart failure (INH) study. Eur J Heart Fail 19(3):314-323. https://doi.org/10.1002/ejhf.706

16. Angermann CE et al (2011) Somatic correlates of comorbid major depression in patients with systolic heart failure. Int J Cardiol 147(1):66-73. https://doi.org/10.1016/j.ijcard.2009.07.044

17. Tsigos C et al (2000) Stress: endocrine physiology and pathophysiology. In: Feingold KR, Anawalt B, Boyce $A$ et al (eds) Endotext. MDText.com, Inc., South Dartmouth (MA)

18. Penninx BW, Milaneschi Y, Lamers F, Vogelzangs $N$ (2013) Understanding the somatic consequences of depression: biological mechanisms and the role of depression symptom profile. BMC Med 11:129. https://doi.org/10.1186/1741-7015-11-129

19. Conte M, Petraglia L, Campana P et al (2020) The role of inflammation and metabolic risk factors in the pathogenesis of calcific aortic valve stenosis. Aging Clin Exp Res. https://doi.org/10.1007/ s40520-020-01681-2

20. Bäz L, Wiesel M, Möbius-Winkler S et al (2020) Depression and anxiety in elderly patients with severe symptomatic aortic stenosis persistently improves after transcatheter aortic valve replacement (TAVR). Int J Cardiol 309:48-54. https://doi. org/10.1016/j.ijcard.2020.03.021

21. Kahl KG, Hueper K, Schweiger U et al (2014) Pericardial, intra-abdominal, and subcutaneous adipose tissue in patients with major depressive disorder. Acta Psychiatr Scand 130(2):137-143. https://doi.org/10.1111/acps.12242

22. Bane C, Hughes CM, McElnay JC (2006) The impact of depressive symptoms and psychosocial factors on medication adherence in cardiovascular disease. Patient Educ Couns 60(2):187-193. https://doi.org/10.1016/j.pec.2005.01.003

23. Thombs BD, Roseman M, Coyne JC etal (2013) Does evidence support the American heart association's recommendation to screen patients for depression in cardiovascular care? An updated systematic review. PLoS One 8(1):e52654. https://doi.org/10. 1371/journal.pone.0052654

24. Angermann CE et al (2020) Pulmonary artery pressure-guided therapy in ambulatory patients with symptomatic heart failure: the CardioMEMS European monitoring study for heart failure (MEMS-HF). Eur J Heart Fail 22(10):1891-1901 https://doi.org/10.1002/ejhf.1943

25. Piña IL, Di Palo KE, Ventura HO (2018) Psychopharmacology and cardiovascular disease. J Am Coll Cardiol 71(20):2346-2359. https://doi.org/10. 1016/j.jacc.2018.03.458

26. Villa RF, Ferrari F, Moretti A (2018) Post-stroke depression: mechanisms and pharmacological treatment. Pharmacol Ther 184:131-144. https:// doi.org/10.1016/j.pharmthera.2017.11.005

27. Angermann CE, Gelbrich G, Stork S et al (2016) Effect of escitalopram on all-cause mortality and hospitalization in patients with heart failure and depression: the MOOD-HF randomized clinical trial. JAMA 315(24):2683-2693. https://doi.org/ 10.1001/jama.2016.7635

28. O'Connor CM, Jiang W, Kuchibhatla M et al (2010) Safety and efficacy of sertraline for depression in patients with heart failure: results of the SADHARTCHF (sertraline against depression and heart disease in chronic heart failure) trial. J Am Coll Cardiol 56(9):692-699. https://doi.org/10.1016/j. jacc.2010.03.068

29. Kahl KG (2018) Direct and indirect effects of psychopharmacological treatment on the cardiovascular system. Horm Mol Biol Clin Investig. https://doi.org/10.1515/hmbci-2018-0054 
30. HeW et al (2019) Effect of antidepressants on death in patients with heart failure: a systematic review and meta-analysis. Heart Fail Rev. https://doi.org/ 10.1007/s10741-019-09850-w

31. Nair GM, Skaria DS, James T, Kanthlal SK (2019) Clozapine disrupts endothelial nitric oxide signaling and antioxidant system for its cardiovascular complications. Drug Res (Stuttg) 69(12):695-698. https://doi.org/10.1055/a-0991-7684

32. Nicol GE et al (2018) Metabolic effects of antipsychotics on adiposity and insulin sensitivity in youths: a randomized clinical trial. JAMA Psychiatry 75(8):788-796. https://doi.org/10. 1001/jamapsychiatry.2018.1088

33. Zuzarte P, Duong A, Figueira ML et al (2018) Current therapeutic approaches for targeting inflammation in depression and cardiovascular disease. Curr Drug Metab 19(8):674-687. https:// doi.org/10.2174/1389200219666180305143501

34. Nidorf SM et al (2020) Colchicine in patients with chronic coronary disease. N Engl J Med. https:// doi.org/10.1056/NEJMoa2021372

35. Ghadri JR, Wittstein IS, Prasad A et al (2018) International expert consensus document on Takotsubo syndrome (part I): clinical characteristics, diagnostic criteria, and pathophysiology. Eur Heart J 39(22):2032-2046. https://doi.org/10. 1093/eurheartj/ehy076

36. Medina de Chazal H, Del Buono MG, KeyserMarcus L et al (2018) Stress cardiomyopathy diagnosis and treatment: JACC state-of-the-art review. J Am Coll Cardiol 72(16):1955-1971. https://doi.org/10.1016/j.jacc.2018.07.072

37. Prasad A, Dangas G, Srinivasan M et al (2014) Incidence and angiographic characteristics of patients with apical ballooning syndrome (takotsubo/ stress cardiomyopathy) in the HORIZONS-AMI trial: an analysis from a multicenter, international study of ST-elevation myocardial infarction. Catheter Cardiovasc Interv 83(3):343-348. https://doi.org/ $10.1002 / \mathrm{ccd} .23441$

38. Templin C, Ghadri JR, Diekmann J et al (2015) Clinical features and outcomes of takotsubo (stress) cardiomyopathy. N Engl J Med 373(10):929-938. https://doi.org/10.1056/NEJMoa1406761

39. Stiermaier T, Moeller C, Oehler K et al (2016) Longterm excess mortality in takotsubo cardiomyopathy: predictors, causes and clinical consequences. Eur J Heart Fail 18(6):650-656. https://doi.org/10. 1002/ejhf.494

40. Templin C, Hänggi J, Klein C et al (2019) Altered limbic and autonomic processing supports brainheart axis in Takotsubo syndrome. Eur Heart J 40(15):1183-1187. https://doi.org/10.1093/ eurheartj/ehz068

41. Kume T, Kawamoto $\mathrm{T}$, Okura $\mathrm{H}$ et al (2008) Local release of catecholamines from the hearts of patients with tako-tsubo-like left ventricular dysfunction. Circ J 72(1):106-108. https://doi.org/ 10.1253/circj.72.106

42. Borchert T et al (2017) Catecholamine-dependent $\beta$-Adrenergic signaling in a pluripotent stem cell model of Takotsubo cardiomyopathy. J Am Coll Cardiol 70(8):975-991. https://doi.org/10.1016/j. jacc.2017.06.061

43. Komesaroff PA et al (1999) Estrogen supplementation attenuates glucocorticoid and catecholamine responses to mental stress in perimenopausal women. J Clin Endocrinol Metab 84(2):606-610. https://doi.org/10.1210/jcem.84.2.5447

44. GhadriJRetal (2017) Anovel clinical score (InterTAK diagnostic score) to differentiate takotsubo syndrome from acute coronary syndrome: results from the international Takotsubo registry. Eur J
Heart Fail 19(8):1036-1042. https://doi.org/10. 1002/ejhf.683

45. Nayeri A, Rafla-Yuan E, Krishnan S et al (2018) Psychiatric illness in Takotsubo (stress) cardiomyopathy: a review. Psychosomatics 59(3):220-226. https://doi.org/10.1016/j.psym.2018.01.011

46. Dias A, Franco E, Figueredo VM et al (2014) Occurrence of Takotsubo cardiomyopathy and use of antidepressants. Int J Cardiol 174(2):433-436 https://doi.org/10.1016/j.ijcard.2014.04.028

47. Davis MB, Arany Z, McNamara DM et al (2020) Peripartum cardiomyopathy: JACC state-of-theart review. J Am Coll Cardiol 75(2):207-221. https://doi.org/10.1016/j.jacc.2019.11.014

48. Honigberg MC, Givertz MM (2019) Peripartum cardiomyopathy. BMJ 364:k5287. https://doi.org/ 10.1136/bmj.k5287

49. Bauersachs J, König T, van der Meer P et al (2019) Pathophysiology, diagnosis and management of peripartum cardiomyopathy: a position statement from the heart failure association of the European society of cardiology study group on peripartum cardiomyopathy. Eur J Heart Fail 21(7):827-843. https://doi.org/10.1002/ejhf.1493

50. Sliwa K, Petrie MC, van der Meer $P$ et al (2020) Clinical presentation, management, and 6-month outcomes in women with peripartum cardiomyopathy: an ESC EORP registry. Eur Heart J 41(39):3787-3797. https://doi.org/10. 1093/eurheartj/ehaa455

51. Moulig V et al (2019) Long-term follow-up in peripartum cardiomyopathy patients with contemporary treatment: low mortality, high cardiac recovery, but significant cardiovascular comorbidities. Eur J Heart Fail 21(12):1534-1542. https://doi.org/10.1002/ejhf.1624

52. Pfeffer TJ, Pietzsch S, Hilfiker-Kleiner D (2020) Common genetic predisposition for heart failure and cancer. Herz 45(7):632-636. https://doi.org/ 10.1007/s00059-020-04953-9

53. Rosman L, Salmoirago-Blotcher E, Cahill J, Sears SF (2019) Psychosocial adjustment and quality of life in patients with peripartum cardiomyopathy. J Cardiovasc Nurs 34(1):20-28. https://doi.org/10 1097/jcn.0000000000000518

54. Pfeffer TJ, Herrmann J, Berliner D et al (2020) Assessment of major mental disorders in a German peripartum cardiomyopathy cohort. ESC Heart Fail. https://doi.org/10.1002/ehf2.12967

55. Ramírez LA, Pérez-Padilla EA, García-Oscos F et al (2018) A new theory of depression based on the serotonin/kynurenine relationship and the hypothalamicpituitary-adrenal axis. Biomedica 38(3):437-450. https://doi.org/10.7705/ biomedica.v38i3.3688

56. Gorinski N et al (2019) Attenuated palmitoylation of serotonin receptor 5-HT1A affects receptor function and contributes to depression-like behaviors. Nat Commun 10(1):3924. https://doi. org/10.1038/s41467-019-11876-5

57. Weiss HD, Marsh L (2012) Impulse control disorders and compulsive behaviors associated with dopaminergic therapies in Parkinson disease. Neurol Clin Pract 2(4):267-274. https://doi.org/10. 1212/CPJ.0b013e318278be9b

58. Hilfiker-Kleiner D, Haghikia A, Berliner Det al (2017) Bromocriptine for the treatment of peripartum cardiomyopathy: a multicentre randomized study. Eur Heart J 38(35):2671-2679. https://doi.org/10. 1093/eurheartj/ehx355

59. Go AS, Hylek EM, Phillips KA et al (2001) Prevalence of diagnosed atrial fibrillation in adults: national implications for rhythm management and stroke prevention: the AnTicoagulation and risk factors in atrial fibrillation (ATRIA) study. JAMA 285(18):2370-2375. https://doi.org/10.1001/ jama.285.18.2370

60. January CT, Wann LS, Alpert JS et al (2014) 2014 AHA/ACC/HRS guideline for the management of patients with atrial fibrillation: executive summary: a report of the American college of cardiology/American heart association task force on practice guidelines and the heart rhythm society. Circulation 130(23):2071-2104. https:// doi.org/10.1161/cir.0000000000000040

61. de Bruijn RF, Heeringa J, Wolters FJ et al (2015) Association between atrial fibrillation and dementia in the general population. JAMA Neurol 72(11):1288-1294. https://doi.org/10. 1001/jamaneurol.2015.2161

62. Kalantarian S, Stern TA, Mansour M, Ruskin JN (2013) Cognitive impairment associated with atrial fibrillation: a meta-analysis. Ann Intern Med 158(5):338-346. https://doi.org/10.7326/00034819-158-5-201303050-00007

63. Kim D, Yang PS, Yu HT et al (2019) Risk of dementia in stroke-free patients diagnosed with atrial fibrillation: data from a population-based cohort. Eur Heart J 40(28):2313-2323. https://doi.org/10. 1093/eurheartj/ehz386

64. Santangeli P, Di Biase L, Bai R et al (2012) Atrial fibrillation and the risk of incident dementia: a meta-analysis. Heart Rhythm 9(11):1761-1768. https://doi.org/10.1016/j.hrthm.2012.07.026

65. Singh-Manoux A, Fayosse A, Sabia S et al (2017) Atrialfibrillation as a riskfactor for cognitive decline and dementia. Eur Heart J 38(34):2612-2618. https://doi.org/10.1093/eurheartj/ehx208

66. Thacker EL, McKnight B, Psaty BM et al (2013) Atrial fibrillation and cognitive decline: a longitudinal cohort study. Neurology 81(2):119-125. https:// doi.org/10.1212/WNL.0b013e31829a33d1

67. Conen D, Rodondi N, Müller A et al (2019) Relationships of overt and silent brain lesions with cognitive function in patients with atrial fibrillation. J Am Coll Cardiol 73(9):989-999. https://doi.org/10.1016/j.jacc.2018.12.039

68. Chen LY et al (2016) Persistent but not paroxysmal atrial fibrillation is independently associated with lower cognitive function: aRIC study. J Am Coll Cardiol 67(11):1379-1380. https://doi.org/10. 1016/j.jacc.2015.11.064

69. Kim D, Yang P-S, Sung J-H et al (2020) Less dementia after catheter ablation for atrial fibrillation: a nationwide cohort study. Eur Heart J 41(47):4483-4493. https://doi.org/10. 1093/eurheartj/ehaa726

70. Dagres N, Chao TF, Fenelon Get al (2018) European heart rhythm association (EHRA)/heart rhythm society (HRS)/asia pacific heart rhythm society (APHRS)/latin American heart rhythm society (LAHRS) expert consensus on arrhythmias and cognitive function: what is the best practice? Heart Rhythm 15(6):e37-e60. https://doi.org/10.1016/j. hrthm.2018.03.005

71. O'Brien JT, Thomas A (2015) Vascular dementia. Lancet 386(10004):1698-1706. https://doi.org/ 10.1016/s0140-6736(15)00463-8

72. Friberg L, Andersson T, Rosenqvist M (2019) Less dementia and stroke in low-risk patients with atrial fibrillation taking oral anticoagulation. Eur Heart J 40(28):2327-2335. https://doi.org/10. 1093/eurheartj/ehz304 